\title{
The CRP/Albumin Ratio Predicts Survival And Monitors Chemotherapeutic Effectiveness In Patients With Advanced Pancreatic Cancer
}

This article was published in the following Dove Press journal: Cancer Management and Research

\author{
Zhiyao $\operatorname{Fan}^{1-4, *}$ \\ Kun $\operatorname{Fan}^{1-4, *}$ \\ Yitao Gong ${ }^{1-4, *}$ \\ Qiuyi Huang ${ }^{1-4}$ \\ Chao Yang ${ }^{1-4}$ \\ He Cheng ${ }^{1-4}$ \\ Kaizhou Jin ${ }^{1-4}$ \\ Quanxing $\mathrm{Ni}^{1-4}$ \\ Xianjun $\mathrm{Yu}$ (D) $^{1-4}$ \\ Guopei Luo ${ }^{1-4}$ \\ Chen Liu (1D) ${ }^{1-4}$
}

'Department of Pancreatic Surgery, Fudan University Shanghai Cancer

Center, Shanghai, People's Republic of

China; ${ }^{2}$ Department of Oncology,

Shanghai Medical College, Fudan

University, Shanghai, People's Republic of

China; ${ }^{3}$ Shanghai Pancreatic Cancer

Institute, Shanghai, People's Republic of

China; ${ }^{4}$ Pancreatic Cancer Institute,

Fudan University, Shanghai, People's

Republic of China

*These authors contributed equally to this work

Correspondence: Guopei Luo; Chen Liu Department of Pancreatic Surgery, Fudan University Shanghai Cancer Center, 270

Dong An Road, Shanghai 200032, People's

Republic of China

$\mathrm{Tel}+86-2 \mathrm{I}-6403-1446$

Fax +86-2I-6403-1446

Email luoguopei@fudanpci.org;

liuchen@fudanpci.org
Purpose: The CRP/albumin (Alb) ratio, a recently reported predictor, has shown value for prognosis in various human cancers. This study aimed to determine the prognostic value of baseline CRP/Alb and to explore the relevance between postchemotherapy CRP/Alb and the efficacy of chemotherapy in advanced pancreatic cancer patients.

Patients and methods: Five hundred and ninety-five patients diagnosed with locally advanced or metastatic adenocarcinoma of the pancreas were enrolled. Cut-off Finder was used to calculate the best cut-off value for baseline CRP/Alb. The primary endpoint was overall survival, which was analyzed by Kaplan-Meier survival curves with $95 \%$ confidence intervals. The log rank test and Cox proportional hazard model were used to evaluate the univariate and multivariate analyses.

Results: The optimal cut-off value for baseline CRP/Alb was determined to be 0.18 . Both the baseline $\mathrm{CRP} / \mathrm{Alb}(\mathrm{CRP} / \mathrm{Alb} \geq 0.18$ vs. $\mathrm{CRP} / \mathrm{Alb}<0.18$, hazard ratio $[\mathrm{HR}]=2.506$; $p<0.001)$ and postchemotherapy $\mathrm{CRP} / \mathrm{Alb}(\mathrm{CRP} / \mathrm{Alb} \geq 0.18$ vs. $\mathrm{CRP} / \mathrm{Alb}<0.18, \mathrm{HR}=1.854$; $p=0.002$ ) were significant predictors of overall survival according to multivariate analysis and were independent of other factors. Patients with a baseline and postchemotherapy CRP/ Alb $\geq 0.18$ had the worst prognosis.

Conclusion: $\mathrm{CRP} / \mathrm{Alb}$ is a strong and useful indicator of prognosis for advanced pancreatic cancer. Both baseline and postchemotherapy CRP/Alb can be used in predicting the survival of patients and monitoring the effectiveness of chemotherapy in clinical practice.

Keywords: CRP/Alb ratio, pancreatic cancer, prognosis, chemotherapy

\section{Introduction}

Pancreatic cancer, which is considered one of the most deadly and aggressive malignant tumors, has risen gradually to become the 4th leading cause of cancerrelated death worldwide. ${ }^{1-3}$ The annual incidence of this disease is approximately equal to its annual mortality rate, and the overall 5 -year survival rate is only $8 \%{ }^{1}$ According to the statistics, only $10-20 \%$ of the patients suffering from pancreatic cancer have a chance to undergo radical surgery. ${ }^{4}$ Therefore, more than $80 \%$ of patients are at the advanced stage at the onset of diagnosis, and chemotherapy is one of the most crucial treatments for them. ${ }^{5}$ Currently, one of the most important prognostic factors for pancreatic cancer is the tumor-node-metastasis (TNM) staging system, which is suggested to play an important role in clinical practice. In addition, a great deal of research on identifying other novel indicators has emerged in recent years. ${ }^{6-8}$ Notwithstanding, for patients suffering from advanced 
pancreatic cancer, there is limited knowledge about predictive factors that can predict the prognosis and chemotherapy response.

Previous research has demonstrated that systemic inflammatory responses play a pivotal part in the progression of various malignancies and are closely related to poor prognosis in patients. ${ }^{9,10}$ Multiple inflammatory markers that are used to predict the prognosis of patients with malignant tumors can be obtained easily from peripheral blood samples; ${ }^{11}$ these predictive indices include the modified Glasgow prognostic score (mGPS), ${ }^{12}$ platelet-lymphocyte ratio (PLR), ${ }^{13}$ and neutrophil-lymphocyte ratio (NLR). ${ }^{14}$ Among these inflammatory markers, the C-reactive protein/albumin (CRP/Alb) ratio has been demonstrated as a prognostic indicator for several cancers, such as hepatocellular carcinoma, ${ }^{15}$ esophageal cancer ${ }^{16}$ gastric cancer, ${ }^{17}$ lung cancer, ${ }^{18}$ newly diagnosed pancreatic cancer, ${ }^{19}$ renal cancer, ${ }^{20}$ and ovarian cancer. ${ }^{21}$ However, its role in predicting prognosis and accessing chemotherapeutic effectiveness has not yet been elucidated in patients with advanced pancreatic cancer.

This study aimed to determine the prognostic value of baseline CRP/Alb and to explore the relevance between postchemotherapy CRP/ALB and the efficacy of chemotherapy in advanced pancreatic cancer patients.

\section{Research Design}

A retrospective, follow-up cohort analysis was performed on patients with locally advanced or metastatic adenocarcinoma of the pancreas from March 2011 to September 2016 at Shanghai Cancer Center, Fudan University, China. According to the American Joint Committee on Cancer (AJCC), 7th edition, TNM staging for pancreatic cancer, locally advanced pancreatic cancer is defined as a tumor involving the celiac axis or the superior mesenteric artery or common hepatic artery without distant metastasis. ${ }^{22}$ All patients involved were diagnosed according to histologic or cytologic evidence. Exclusion criteria included the following: patients with prior treatment for primary tumors and major metastases, patients without follow-up data or who were lacking serum CRP and albumin levels at diagnosis, and patients with second malignancies or multiple primary malignancies or evidence of infection or other inflammatory conditions. Surviving patients with a follow-up time of less than 6 months were also excluded. In total, 595 patients were recruited for our cohort. Most of the patients enrolled
$(485 / 595,81.5 \%)$ underwent chemotherapy, and 92.6\% of them (449/485) were treated with gemcitabine-based chemotherapy. The remaining $7.4 \%(36 / 485)$ were subjected to other chemotherapy protocols. Chemotherapy patients are patients who receive 2 or more cycles of chemotherapy. For patients who have never received chemotherapy, the variable of chemotherapy appears to be a no. All chemotherapy was based on the latest version of the National Comprehensive Cancer Network (NCCN) Guidelines.

Clinicopathological data, including sex, age, tumor diameter, tumor location, disease stage, and serum CA19-9 concentration, were collected from the patients' medical history from Shanghai Cancer Center. The baseline serum levels of CRP and Alb used for evaluation were determined prior to the initial treatment. The CRP/Alb ratio was defined as the serum concentration of CRP $(\mathrm{mg} / \mathrm{L})$ divided by that of $\mathrm{Alb}(\mathrm{g} / \mathrm{L})$. The postchemotherapy CRP/Alb ratio after two cycles of chemotherapy was also calculated. All patients were regularly followed-up by telephone. The onset of follow-up was the date of the first diagnosis of pancreatic cancer, and the terminal date was December 2017 or death. This retrospective study was

Table I Clinicopathologic Characteristics Of All Patients

\begin{tabular}{|c|c|c|c|c|}
\hline Variables & $\mathbf{n}$ & $\begin{array}{l}\text { CRPI } \\
\text { Alb }<0.18\end{array}$ & $\begin{array}{l}\text { CRP/ } \\
\text { Alb } \geq 0.18\end{array}$ & $p$ value \\
\hline Patients (N) & 595 & $392(65.9 \%)$ & 203 (34.1\%) & \\
\hline Sex & & & & 0.062 \\
\hline Male & 380 & $240(61.2 \%)$ & 140 (69.0\%) & \\
\hline Female & 215 & $152(38.8 \%)$ & $63(31.0 \%)$ & \\
\hline Age (years) & & & & 0.249 \\
\hline$\geq 65$ & 233 & I 47 (37.5\%) & $86(42.4 \%)$ & \\
\hline$<65$ & 362 & 245 (62.5\%) & II (57.6\%) & \\
\hline Location of tumor & & & & 0.025 \\
\hline Head & 197 & 142 (36.2\%) & $55(27.1 \%)$ & \\
\hline Body or tail & 398 & $250(63.8 \%)$ & I 48 (72.9\%) & \\
\hline Tumor diameter $(\mathrm{cm})$ & & & & $<0.001$ \\
\hline$<4$ & 258 & I9I (48.7\%) & 67 (33.0\%) & \\
\hline$\geq 4$ & 337 & 201 (5I.3\%) & I 36 (67.0\%) & \\
\hline Tumor spread & & & & $<0.001$ \\
\hline Locally advanced & 388 & $226(57.7 \%)$ & $162(79.8 \%)$ & \\
\hline Metastatic & 207 & $166(42.3 \%)$ & 41 (20.2\%) & \\
\hline CAI9-9 (U/mL) & & & & 0.151 \\
\hline$<37$ & 116 & $83(21.2 \%)$ & $33(16.2 \%)$ & \\
\hline$\geq 37$ & 479 & $309(78.8 \%)$ & 170 (83.8\%) & \\
\hline
\end{tabular}

Abbreviation: CRP/Alb, C-reactive protein/albumin ratio. 
approved by the Ethics Board of Shanghai Cancer Center, Fudan University. The patient/next of kin consent was written informed consent, and this study was conducted in accordance with the Declaration of Helsinki.

\section{Statistical Analysis}

Overall survival (OS) was the primary endpoint, and it was considered to be the time between the first date of diagnosis and the date of death for any reason. OS was analyzed using Kaplan-Meier survival curves with 95\% confidence intervals (CIs). Univariate and multivariate analyses were calculated according to the log rank test and the Cox proportional hazard model, respectively. Clinicopathologic characteristics between groups were compared using the Pearson $\chi^{2}$ or Fisher's exact tests. The optimal cut-off values for baseline CRP/Alb were determined using an $\mathrm{R}$ software-engineered, web-based system designed by Budczies $\mathrm{J}$ et al. ${ }^{23}$ Statistical analyses were performed using SPSS 17.0 software (SPSS, Inc., Chicago, IL). Differences were considered statistically significant at $\mathrm{p}<0.05$.

\section{Results}

The general information and clinical indexes of the patients included in the cohort are listed in Table 1. All patients received a histological or cytological diagnosis for primary pancreatic lesions or metastases. Of all the patients, 380 (63.9\%) were males, and 215 (36.1\%) were females. The median age of the patients recruited at diagnosis was 62 years old (range 33-84), and the numbers of patients with locally advanced and metastatic disease were 207 (34.8\%) and 388 (65.2\%), respectively.

Table 2 Univariate And Multivariate Analyses For The Overall Survival Of All Patients According To Baseline CRP/Alb

\begin{tabular}{|c|c|c|c|c|c|c|c|}
\hline \multirow[t]{2}{*}{ Variables } & \multirow[t]{2}{*}{$\mathbf{n}$} & \multicolumn{3}{|c|}{ Univariate Analysis } & \multicolumn{3}{|c|}{ Multivariate Analysis } \\
\hline & & HR & $95 \% \mathrm{Cl}$ & $p$ value & HR & $95 \% \mathrm{Cl}$ & $p$ value \\
\hline Entire cohort & 595 & & & & & & \\
\hline $\begin{array}{l}\text { Age (years) } \\
\quad<65 \\
\geq 65\end{array}$ & $\begin{array}{l}233 \\
362\end{array}$ & $\begin{array}{l}\mathrm{I} \\
1.034\end{array}$ & $0.857-1.248$ & 0.724 & & & \\
\hline $\begin{array}{l}\text { Location of tumor } \\
\text { Body or tail } \\
\text { Head }\end{array}$ & $\begin{array}{l}398 \\
197\end{array}$ & $\begin{array}{l}1 \\
1.009\end{array}$ & $0.832-1.224$ & 0.928 & & & \\
\hline $\begin{array}{l}\text { Sex } \\
\text { Female } \\
\text { Male }\end{array}$ & $\begin{array}{l}215 \\
380\end{array}$ & $\begin{array}{l}1 \\
1.139\end{array}$ & $0.942-1.379$ & 0.180 & $\begin{array}{l}1 \\
1.114\end{array}$ & $0.920-1.350$ & 0.268 \\
\hline $\begin{array}{l}\text { Tumor diameter }(\mathrm{cm}) \\
\quad<4 \\
\geq 4\end{array}$ & $\begin{array}{l}258 \\
337\end{array}$ & $\begin{array}{l}\mathrm{I} \\
\mathrm{I} .468\end{array}$ & $1.218-1.768$ & $<0.001$ & $\begin{array}{l}\mathrm{I} \\
\mathrm{I} .276\end{array}$ & $1.054-1.544$ & 0.012 \\
\hline $\begin{array}{l}\text { Chemotherapy } \\
\text { Yes } \\
\text { No }\end{array}$ & $\begin{array}{l}485 \\
110\end{array}$ & $\begin{array}{l}\mathrm{I} \\
\mathrm{I} .562\end{array}$ & $1.246-1.958$ & $<0.001$ & $\begin{array}{l}1 \\
1.393\end{array}$ & $1.103-1.758$ & 0.005 \\
\hline $\begin{array}{l}\text { CAI9-9 }(\mathrm{U} / \mathrm{mL}) \\
\quad<37 \\
\geq 37\end{array}$ & $\begin{array}{l}116 \\
479\end{array}$ & $\begin{array}{l}\mathrm{I} \\
1.588\end{array}$ & $1.234-2.043$ & $<0.001$ & $\begin{array}{l}\mathrm{I} \\
1.593\end{array}$ & $1.236-2.053$ & $<0.001$ \\
\hline $\begin{array}{l}\text { Tumor spread } \\
\text { Locally advanced } \\
\text { Metastatic }\end{array}$ & $\begin{array}{l}207 \\
388\end{array}$ & $\begin{array}{l}1 \\
2.048\end{array}$ & $|.67|-2.509$ & $<0.001$ & $\begin{array}{l}\mathrm{I} \\
1.829\end{array}$ & $1.488-2.249$ & $<0.001$ \\
\hline $\begin{array}{l}\text { Baseline CRP/Alb } \\
\quad<0.18 \\
\geq 0.18\end{array}$ & $\begin{array}{l}392 \\
203\end{array}$ & $\begin{array}{l}1 \\
2.237\end{array}$ & I.849-2.706 & $<0.001$ & $\begin{array}{l}\mathrm{I} \\
\mathrm{I} .840\end{array}$ & $1.510-2.242$ & $<0.001$ \\
\hline
\end{tabular}

Abbreviations: HR, hazard ratio; CRP/Alb, C-reactive protein/albumin ratio. 
The median tumor size was $4.2 \mathrm{~cm}$, and the tumor size was $\geq 4 \mathrm{~cm}$ in 337 patients $(56.6 \%)$. One hundred ninetyseven patients $(33.1 \%)$ had primary pancreatic head tumors. The serum levels of CA-199 in 116 patients $(19.5 \%)$ were within the normal range $(<37 \mathrm{U} / \mathrm{mL})$. The median baseline CRP/Alb was 0.08 (range 0-7.02), and the optimal cut-off value for baseline CRP/Alb was calculated to be 0.18 for the OS using the biostatistical tool Cut-off Finder. ${ }^{23}$ The patients were divided into two cohorts by cut-off values according to the baseline CRP/Alb. A total of 203 (34.1\%) patients had baseline $\mathrm{CRP} / \mathrm{Alb}$ levels higher than the cut-off value. Correlations between the $\mathrm{CRP} / \mathrm{Alb}$ ratio and the clinicopathological characteristics were analyzed using $\chi 2$ tests, as shown in Table 1 . The baseline CRP/Alb ratio was not associated with age $(\mathrm{p}=0.249)$. It was, however, associated with tumor location $(\mathrm{p}=0.025)$, tumor diameter $(p<0.001)$ and disease stage $(p<0.001)$. Although there was no significant difference, male patients $(p=0.062)$ and patients with elevated CA19-9 levels $(\mathrm{p}=0.151)$ showed a tendency for a higher CRP/Alb ratio.

The median follow-up time of the present study was 7.3 months, and the median survival time was 7.6 months. The 1-year OS and 2-year OS were 18.0 and $24.1 \%$, respectively. Table 2 indicates the relationship between the clinicopathological variables and OS. In the univariate analysis, the OS was significantly correlated with tumor diameter, disease stage, CA19-9 level, chemotherapy and baseline CRP/Alb. Although not statistically significant, male patients presented with a worse prognosis trend. The multivariate analysis revealed the following as independent prognostic factors for OS: tumor diameter $\geq 4 \mathrm{~cm}$ $(\mathrm{HR}=1.276 ; \mathrm{p}=0.012)$, lack of chemotherapy $(\mathrm{HR}=1.393 ; \mathrm{p}=0.005), \mathrm{CA} 19-9 \geq 37 \mathrm{U} / \mathrm{mL}(\mathrm{HR}=$ 1.593; $\mathrm{p}<0.001)$, metastatic diseases $(\mathrm{HR}=1.829$; $\mathrm{p}<0.001)$ and baseline $\mathrm{CRP} / \mathrm{Alb} \geq 0.18(\mathrm{HR}=1.840$; $\mathrm{p}<0.001)$. Survival was significantly better for patients with a baseline $\mathrm{CRP} / \mathrm{Alb}$ ratio $<0.18$ than for those with a baseline $\mathrm{CRP} / \mathrm{Alb}$ ratio $\geq 0.18$, as shown in Figure $1 \mathrm{~A}$. Regardless of the locally advanced or metastatic cohort classification, prognosis was significantly worse for patients with a baseline $\mathrm{CRP} / \mathrm{Alb} \geq 0.18$ than for those with a baseline $\mathrm{CRP} / \mathrm{Alb}<0.180$ (Figure $1 \mathrm{~B}$ and $\mathrm{C}$ ).

Two hundred thirteen patients had $\mathrm{CRP} / \mathrm{Alb}$ ratio data after two cycles of chemotherapy. According to a univariate

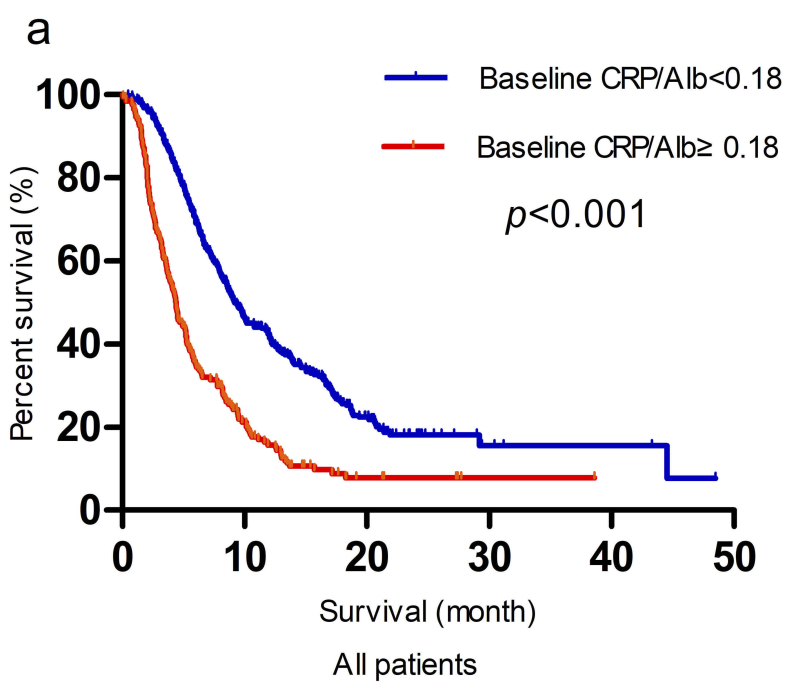

b
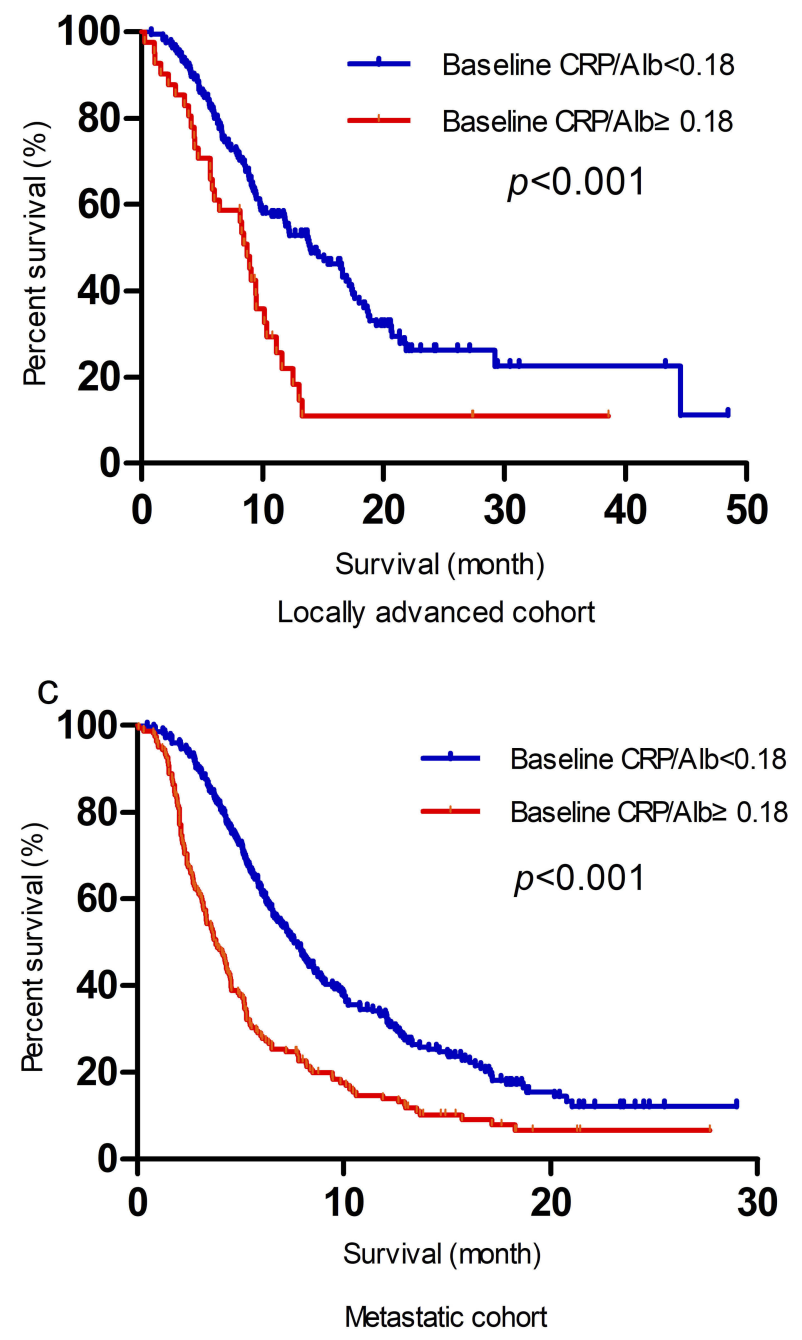

Figure I Kaplan-Meier analysis of OS according to baseline CRP/Alb in all patients (A), in the locally advanced (B) and metastatic cohorts (C). 
Table 3 Univariate And Multivariate Analyses For The Overall Survival Of Patients According To Baseline And Postchemotherapy CRP/Alb

\begin{tabular}{|c|c|c|c|c|c|c|c|}
\hline \multirow[t]{2}{*}{ Variables } & \multirow[t]{2}{*}{ n } & \multicolumn{3}{|c|}{ Univariate Analysis } & \multicolumn{3}{|c|}{ Multivariate Analysis } \\
\hline & & HR & $95 \% \mathrm{Cl}$ & $p$ value & HR & $95 \% \mathrm{Cl}$ & $p$ value \\
\hline Entire cohort & 213 & & & & & & \\
\hline $\begin{array}{l}\text { Age (years) } \\
\quad<65 \\
\geq 65\end{array}$ & $\begin{array}{l}142 \\
71\end{array}$ & $\begin{array}{l}1 \\
1.087\end{array}$ & $0.756-1.563$ & 0.653 & & & \\
\hline $\begin{array}{l}\text { Location of tumor } \\
\text { Body or tail } \\
\text { Head }\end{array}$ & $\begin{array}{l}137 \\
76\end{array}$ & $\begin{array}{l}1 \\
1.006\end{array}$ & $0.716-1.413$ & 0.972 & & & \\
\hline $\begin{array}{l}\text { Sex } \\
\qquad \text { Female } \\
\text { Male }\end{array}$ & $\begin{array}{l}73 \\
140\end{array}$ & $\begin{array}{l}1 \\
1.339\end{array}$ & $0.940-1.907$ & 0.105 & $\begin{array}{l}1 \\
1.207\end{array}$ & $0.842-1.73 \mid$ & 0.306 \\
\hline $\begin{array}{l}\text { Tumor diameter }(\mathrm{cm}) \\
\quad<4 \\
\geq 4\end{array}$ & $\begin{array}{l}102 \\
111\end{array}$ & 1 & $0.916-1.769$ & 0.150 & $\begin{array}{l}1 \\
1.072\end{array}$ & $0.76-1.513$ & 0.691 \\
\hline $\begin{array}{l}\text { CAI9-9 }(\mathrm{U} / \mathrm{mL}) \\
\quad<37 \\
\geq 37\end{array}$ & $\begin{array}{l}47 \\
166\end{array}$ & 1 & $0.902-2.090$ & 0.139 & $\begin{array}{l}1 \\
1.486\end{array}$ & $0.97 I-2.275$ & 0.068 \\
\hline $\begin{array}{l}\text { Tumor spread } \\
\text { Locally advanced } \\
\text { Metastatic }\end{array}$ & $\begin{array}{l}80 \\
133\end{array}$ & $\begin{array}{l}1 \\
2.140\end{array}$ & $1.492-3.609$ & $<0.001$ & $\begin{array}{l}1 \\
1.926\end{array}$ & $1.330-2.790$ & 0.001 \\
\hline $\begin{array}{l}\text { CRP/Alb } \\
\text { Baseline }<0.18 \text { Postchemotherapy }<0.18 \\
\text { Baseline } \geq 0.18 \text { Postchemotherapy }<0.18 \\
\text { Baseline }<0.18 \text { Postchemotherapy } \geq 0.18 \\
\text { Baseline } \geq 0.18 \text { Postchemotherapy } \geq 0.18\end{array}$ & $\begin{array}{l}135 \\
17 \\
29 \\
32\end{array}$ & $\begin{array}{l}1 \\
1.582 \\
2.272 \\
3.639\end{array}$ & $\begin{array}{l}0.861-2.908 \\
1.447-3.568 \\
2.310-5.732\end{array}$ & $\begin{array}{l}0.140 \\
<0.001 \\
<0.001\end{array}$ & $\begin{array}{l}1 \\
1.356 \\
2.158 \\
3.132\end{array}$ & $\begin{array}{l}0.725-2.536 \\
1.355-3.437 \\
1.952-5.025\end{array}$ & $\begin{array}{l}0.341 \\
0.001 \\
<0.001\end{array}$ \\
\hline
\end{tabular}

Note: Two hundred and thirteen patients had postchemotherapy CRP/Alb ratio data after two cycles of chemotherapy.

Abbreviations: HR, hazard ratio; CRP/Alb C-reactive protein/albumin ratio.

analysis, male patients $(\mathrm{HR}=1.339 ; \mathrm{p}=0.105)$ with a tumor diameter $\geq 4 \mathrm{~cm}(\mathrm{HR}=1.273 ; \mathrm{p}=0.150)$ and $\mathrm{CA} 19-9 \geq 37 \mathrm{U} /$ $\mathrm{mL}(\mathrm{HR}=1.373 ; \mathrm{p}=0.139)$ had a worse prognosis trend. Disease stage and postchemotherapy CRP/Alb were significant independent predictors of OS according to both univariate analysis and multivariate analysis (Table 3). The clinical value of postchemotherapy $\mathrm{CRP} / \mathrm{Alb}(\mathrm{HR}=2.456 ; \mathrm{p}<0.001$ (Figure 2A)) in predicting the prognosis of patients after two cycles of chemotherapy was better than that of baseline CRP/ Alb (HR $=1.890 ; p=0.001)$. To confirm the value of CRP/ Alb for monitoring chemotherapeutic effectiveness, the patients were further divided into 4 subgroups according to whether the baseline and postchemotherapy $\mathrm{CRP} / \mathrm{Alb}$ ratios were $\geq 0.18$. Among the 4 subgroups, the patients with baseline and postchemotherapy $\mathrm{CRP} / \mathrm{Alb}$ ratios $\geq 0.18$ had the worst prognosis $(\mathrm{HR}=3.132 ; \mathrm{p}<0.001)$, followed by patients with baseline CRP/Alb ratios $<0.18$ and postchemotherapy $\mathrm{CRP} / \mathrm{Alb}$ ratios $\geq 0.18$ (HR $=2.158 ; \mathrm{p}=0.001$ (Figure 2B)). No significant differences were observed for OS between patients with baseline and postchemotherapy $\mathrm{CRP} / \mathrm{Alb}$ ratios $<0.18$ and patients with baseline CRP/Alb ratios $\geq 0.18$ and postchemotherapy $\mathrm{CRP} / \mathrm{Alb}$ ratios $<0.18$ $(\mathrm{HR}=1.356 ; \mathrm{p}=0.341)$.

\section{Discussion}

Because of both the cell-intrinsic and cell-extrinsic processes of cancer cells, cancer is regarded as a complicated disease. ${ }^{9}$ Inflammation can promote tumorigenesis and development by affecting the microenvironment of cancer. ${ }^{10}$ Studies have shown that some inflammatory mediators, such as acute phase and inflammatory proteins, chemokines, immune cells and cytokines, ${ }^{24,25}$ play a 


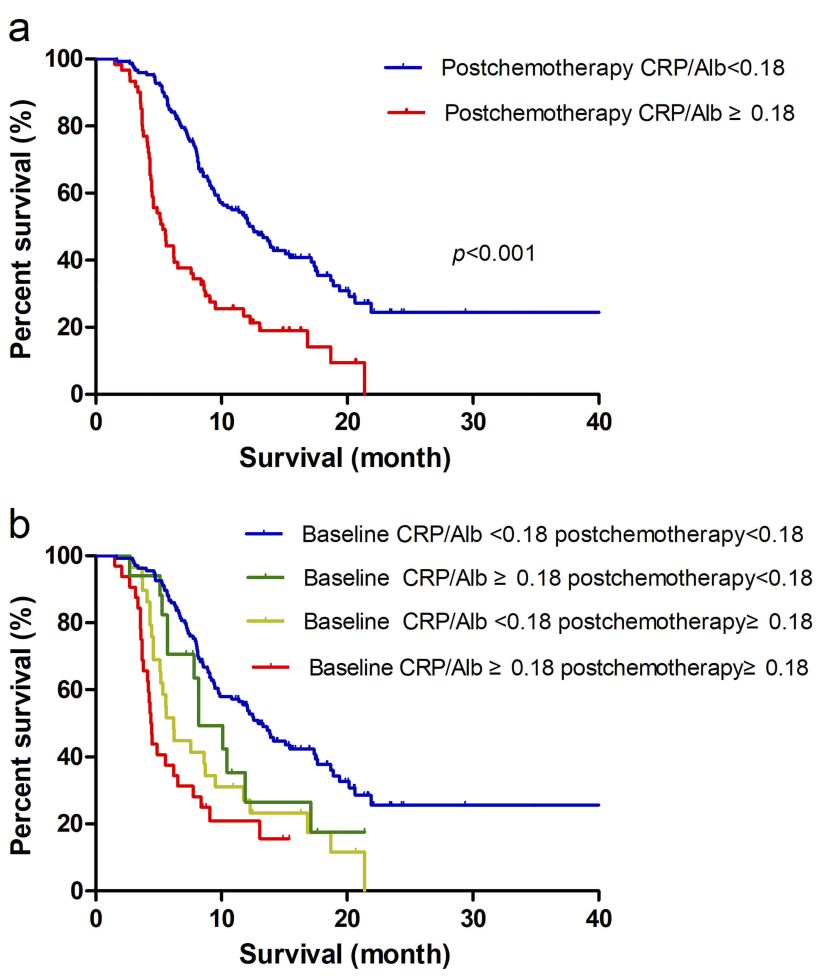

Figure 2 (A) Kaplan-Meier analysis of OS in patients after two cycles of chemotherapy according to postchemotherapy CRP/Alb. (B) OS of the patients after two cycles of chemotherapy according to baseline and postchemotherapy CRP/Alb.

pivotal role in cancer development, angiogenesis, invasion and metastasis. A variety of inflammatory markers, including NLR, PLR, CRP/Alb and mGPS, have been used to evaluate the outcome of pancreatic cancer. $6,19,26$

As an acute phase protein, CRP is synthesized in the liver and induced by pro-inflammatory cytokines, and is considered to be a predictor of infection. It can also elevated in the metastasis process of tumors. Alb is a circulating protein in the plasma that can be involved in the inflammatory response. $^{27}$ The CRP/Alb ratio can represent the potential inflammatory status of the body. It was developed as a prognostic score for patients with sepsis and was later widely used for various neoplastic diseases..$^{20,28,29}$ It is widely acknowledged that the inflammatory response and innutrition are closely associated with low quality of life and have detrimental effects on therapeutic efficacy in cancer patients. ${ }^{30,31}$ As a quantifiable continuous variable, $\mathrm{CRP} / \mathrm{Alb}$ can reflect the inflammation and nutritional status of cancer patients during treatment. A study showed that for patients who underwent pancreatic resection, a higher $\mathrm{CRP} / \mathrm{Alb}$ ratio was a useful and remarkable predictor of poor OS. ${ }^{29}$ However, studies on the prognostic value of baseline and postchemotherapy CRP/Alb for final outcomes for advanced pancreatic cancer patients after chemotherapy are rare. ${ }^{28}$
Our study used multivariate analyses to demonstrate that both baseline and postchemotherapy CRP/Alb ratios were independent predictors of the estimated final prognosis for advanced pancreatic cancer patients after chemotherapy. Furthermore, in the subsequent subgroup assessment, patients with baseline CRP/Alb $<0.180$ showed a notably better clinical outcome than patients with baseline CRP/Alb $\geq 0.18$, regardless of their locally advanced or metastatic cohort classification. Postchemotherapy CRP/Alb is better than baseline CRP/Alb for predicting survival and can help us to predict the chemotherapy response in a timely manner. Patients with baseline CRP/Alb $\geq 0.18$ and postchemotherapy $\mathrm{CRP} / \mathrm{Alb}<0.18$, which means they could benefit from chemotherapy, have similar prognoses as patients with baseline and postchemotherapy $\mathrm{CRP} / \mathrm{Alb}<0.18$. In addition, patients with baseline and postchemotherapy $\mathrm{CRP} / \mathrm{Alb} \geq 0.18$ had a HR of 3.132, suggesting that baseline and postchemotherapy $\mathrm{CRP} / \mathrm{Alb}$ ratios $\geq 0.18$ are the most useful and important prognostic factors for patients receiving chemotherapy.

Our present research first discussed the role of CRP/ Alb in indicating the outcomes for advanced pancreatic cancer patients who have received chemotherapy. In addition, we found that postchemotherapy CRP/Alb can be used for both monitoring the effectiveness of chemotherapy and predicting the survival of patients with advanced pancreatic cancer. As chemotherapy is the main alternative treatment for these patients and it's effectiveness is closely related to patient's final outcome, it is very important to find a simple and effective method to predict the effect of chemotherapy. This tool could help to identify which groups of advanced pancreatic cancer patients will benefit most from chemotherapy and help doctors make clinical decisions. We set 0.18 as the CRP/Alb cut-off value by using Cut-off Finder, but other studies have set different cut-off values. These variations may be related to the different background characteristics of the patients.

There were some limitations to this study. First, because CRP is not a unique biomarker for inflammation, it could be elevated in a large number of systematic diseases. Second, although our sample size is relatively large compared with other related studies, the sample size becomes relatively small after division into subgroups, which also means that our results need further verification in future multicenter prospective studies.

\section{Conclusion}

$\mathrm{CRP} / \mathrm{Alb}$ is a strong and useful predictor of prognosis for patients with advanced pancreatic cancer. Both baseline 
$\mathrm{CRP} / \mathrm{Alb}$ and postchemotherapy CRP/Alb can be used for monitoring the effectiveness of chemotherapy and predicting survival. CRP can be used as a routine test for decision making during chemotherapy for the clinical treatment of advanced pancreatic cancer.

\section{Funding}

This work was supported by The National Science Fund for Distinguished Young Scholars (grant number 81625016).

\section{Disclosure}

The authors report no conflicts of interest in this work.

\section{References}

1. Siegel RL, Miller KD, Jemal A. Cancer statistics, 2018. CA Cancer J Clin. 2018;68:7-30. doi:10.3322/caac. 21442

2. Hidalgo M. Pancreatic cancer. N Engl J Med. 2010;362(17):16051617. doi:10.1056/NEJMra0901557

3. Audrey V, Joseph H, Rich S, Hruban RH, Michael G. Pancreatic cancer. Lancet. 2011;378(9791):607-620. doi:10.1016/S0140-6736 (10)62307-0

4. Sabater L, Muñoz E, Roselló S, et al. Borderline resectable pancreatic cancer. Challenges and controversies. Cancer Treat Rev. 2018;68:124-135. doi:10.1016/j.ctrv.2018.06.006

5. Neoptolemos JP, Kleeff J, Michl P, Costello E, Greenhalf W, Palmer DH. Therapeutic developments in pancreatic cancer: current and future perspectives. Nat Rev Gastroenterol Hepatol. 2018;15:333348. doi:10.1038/s41575-018-0005-x

6. Luo G, Guo M, Liu Z, et al. Blood neutrophil-lymphocyte ratio predicts survival in patients with advanced pancreatic cancer treated with chemotherapy. Ann Surg Oncol. 2015;22(2):670-676. doi:10.1245/s10434-014-4021-y

7. Jin $\mathrm{W}, \mathrm{Xu} \mathrm{HX}$, Zhang SR, et al. Tumor-infiltrating NETs predict postsurgical survival in patients with pancreatic ductal adenocarcinoma. Ann Surg Oncol. 2018;26(2):635-643.

8. Kruger S, Heinemann V, Ross C, et al. Repeated mutKRAS ctDNA measurements represent a novel and promising tool for early response prediction and therapy monitoring in advanced pancreatic cancer. Ann Oncol. 2018;29(12):2348-2355.

9. Antonioli L, Blandizzi C, Pacher P, Haskó G. Immunity, inflammation and cancer: a leading role for adenosine. Nat Rev Cancer 2013;13(12):842-857. doi:10.1038/nrc3613

10. Pagès F, Galon J, Dieu-Nosjean MC, Tartour E, Sautès-Fridman C, Fridman WH. Immune infiltration in human tumors: a prognostic factor that should not be ignored. Oncogene. 2010;29(8):10931102. doi: $10.1038 /$ onc. 2009.416

11. McMillan DC, Morrison DS, Talwar D, Horgan PG, Proctor MJ. Inflammation-based prognostic scores to predict outcome in patients with cancer. J Clin Oncol. 2011;29(15_suppl):e21154. doi:10.1200/ jco.2011.29.15_suppl.e21154

12. Laird BJ, Kaasa S, McMillan DC, et al. Prognostic factors in patients with advanced cancer: a comparison of clinicopathological factors and the development of an inflammation-based prognostic system. Clin Cancer Res. 2013;19(19):5456-5464. doi:10.1158/1078-0432.CCR-13-1066

13. Lee S, Kwon HC, Kim SH, et al. Capecitabine monotherapy and the clinical significance of neutrophil-lymphocyte ratio versus plateletlymphocyte ratio in patients with metastatic colorectal cancer. $J$ Clin Oncol. 2012;30(4_suppl):660. doi:10.1200/jco.2012.30.4_suppl.660
14. Kim J, Kim HJ. Neutrophil lymphocyte ratio (NLR) change after systemic treatment as a predictive factor of cancer specific survival in stage IV breast cancer. J Clin Oncol. 2015;33(28_suppl):29. doi:10.1200/jco.2015.33.28_suppl.29

15. Kinoshita A, Onoda H, Imai N, et al. The C-reactive protein/albumin ratio, a novel inflammation-based prognostic score, predicts outcomes in patients with hepatocellular carcinoma. Ann Surg Oncol. 2015;22(3):803-810. doi:10.1245/s10434-014-4048-0

16. Wei XL, Wang FH, Zhang DS, et al. A novel inflammation-based prognostic score in esophageal squamous cell carcinoma: the Creactive protein/albumin ratio. BMC Cancer. 2015;15(1):350. doi:10.1186/s12885-015-1584-3

17. Lu J, Xu BB, Zheng ZF, et al. CRP/prealbumin, a novel inflammatory index for predicting recurrence after radical resection in gastric cancer patients: post hoc analysis of a randomized phase III trial. Gastric Cancer. 2018;22(3):536-545.

18. Ni XF, Wu J, Ji M, et al. Effect of C-reactive protein/albumin ratio on prognosis in advanced non-small-cell lung cancer. Asia Pac J Clin Oncol. 2018;14:402-409. doi:10.1111/ajco.2018.14.issue-6

19. Liu Z, Jin K, Guo M, et al. Prognostic value of the CRP/Alb ratio, a novel inflammation-based score in pancreatic cancer. Ann Surg Oncol. 2016;24(2):561-568.

20. Guo $\mathrm{S}, \mathrm{He} X$, Chen $\mathrm{Q}$, et al. The C-reactive protein/albumin ratio, a validated prognostic score, predicts outcome of surgical renal cell carcinoma patients. BMC Cancer. 2017;17(1):171. doi:10.1186/ s12885-017-3119-6

21. Liu Y, Chen S, Zheng C, et al. The prognostic value of the preoperative c-reactive protein/albumin ratio in ovarian cancer. BMC Cancer. 2017;17(1):285. doi:10.1186/s12885-017-3220-x

22. Edge SB, Compton CC. The American Joint Committee on Cancer: the 7th edition of the AJCC cancer staging manual and the future of TNM. Ann Surg Oncol. 2010;17(6):1471-1474. doi:10.1245/s10434010-0985-4

23. Budczies J, Klauschen F, Sinn BV, et al. Cutoff finder: a comprehensive and straightforward web application enabling rapid biomarker cutoff optimization. PLoS One. 2012;7(12):e51862. doi:10.1371/journal.pone. 0051862

24. Catanzaro JM, Sheshadri N, Pan JA, et al. Oncogenic Ras induces inflammatory cytokine production by upregulating the squamous cell carcinoma antigens SerpinB3/B4. Nat Commun. 2014;5:3729. doi:10.1038/ncomms5972

25. Germano G, Allavena P, Mantovani A. Cytokines as a key component of cancer-related inflammation. Cytokine. 2008;43(3):374-379. doi:10.1016/j.cyto.2008.07.014

26. Imaoka H, Mizuno N, Hara K, et al. Evaluation of modified glasgow prognostic score for pancreatic cancer: a retrospective cohort study. Pancreas. 2015;45(2):211-217.

27. Caraceni P, Tufoni M, Bonavita ME. Clinical use of albumin. Blood Transfusion. 2013;11(3):S18-S25. doi:10.2450/2013.005s

28. Wang Y, Xiao X, Wang T, et al. A survival model in locally advanced and metastatic pancreatic ductal adenocarcinoma. J Cancer. 2018;9 (7):1301-1307. doi:10.7150/jca.23984

29. Haruki K, Shiba H, Shirai Y, et al. The C-reactive protein to albumin ratio predicts long-term outcomes in patients with pancreatic cancer after pancreatic resection. World J Surg. 2016;40:2254-2260. doi:10.1007/s00268-016-3491-4

30. Yoshikawa T, Aoyama T, Kuwabara H, et al. Body weight loss after surgery as an independent risk factor for continuation of S-1 adjuvant chemotherapy for gastric cancer. $J$ Clin Oncol. 2012;30 (4_suppl):125. doi:10.1200/jco.2012.30.4_suppl.125

31. Rogers PC. Nutritional status as a prognostic indicator for pediatric malignancies. J Clin Oncol. 2014;32(13):1293-1294. doi:10.1200/ JCO.2014.55.0616 


\section{Publish your work in this journal}

Cancer Management and Research is an international, peer-reviewed open access journal focusing on cancer research and the optimal use of preventative and integrated treatment interventions to achieve improved outcomes, enhanced survival and quality of life for the cancer patient.
The manuscript management system is completely online and includes a very quick and fair peer-review system, which is all easy to use. Visit http://www.dovepress.com/testimonials.php to read real quotes from published authors. 